\title{
The Oxytocin Receptor Gene (OXTR) and Gazing Behavior during Social Interaction: An Observational Study in Young Adults
}

\author{
Maaike Verhagen ${ }^{1}$, Rutger Engels ${ }^{1,2}$, Eeske Van Roekel ${ }^{3}$ \\ ${ }^{1}$ Behavioural Science Institute, Radboud University Nijmegen, Nijmegen, The Netherlands \\ ${ }^{2}$ Trimbos Institute, Utrecht, The Netherlands \\ ${ }^{3}$ Interdisciplinary Center Psychopathology and Emotion Regulation, University Medical Center Groningen, \\ Groningen, The Netherlands \\ Email: $\underline{\text { m.verhagen@bsi.ru.nl }}$
}

Received 10 June 2014; revised 14 July 2014; accepted 1 August 2014

Copyright (C) 2014 by authors and Scientific Research Publishing Inc.

This work is licensed under the Creative Commons Attribution International License (CC BY).

http://creativecommons.org/licenses/by/4.0/

(c) (i) Open Access

\section{Abstract}

Background: In the present study, the relation between a polymorphic marker within the OXTR gene (rs53576) and gazing behavior during two separate social interaction tasks was examined. Gazing behavior was considered to be an integral part of belonging regulation processes. Methods: We conducted an observational interaction study ( $N=116 ; 58$ dyads) in a naturalistic setting. Participants were seated face to face with hidden cameras positioned behind them. Each couple was instructed to have two short conversations about daily topics (nightlife in the city and movies), separated by a distraction task. We studied the role of the OXTR gene in relation to gaze duration (total duration and mean duration per event) at the interaction partner, both for the total interaction and for the first and second halves of the interaction, separately. Results: Analyses showed a significant relationship between the OXTR genetic variant and mean gaze duration at the interaction partner. Individuals carrying an A-allele showed increased gaze duration. This genetic association was particularly present during the first half of the conversation. In the second interaction task, we confirmed the findings that A-allele carriers showed longer mean gaze duration. No associations were found for total gaze duration. Conclusions: The OXTR A-allele was associated with longer mean gaze duration at an unknown interaction partner, especially during the first halves of the interaction times. This might illustrate that A-carriers, compared to GG-homozygous individuals, need slightly more time to read the micro socio-emotional facial cues of a new interaction partner or need more time for social reconciliation processes. This could be indicative of a genetic liability for being less vulnerable to pick up new micro social cues.

\footnotetext{
*Corresponding author.

How to cite this paper: Verhagen, M., Engels, R., \& Van Roekel E. (2014). The Oxytocin Receptor Gene (OXTR) and Gazing Behavior during Social Interaction: An Observational Study in Young Adults. Open Journal of Depression, 3, 136-146.

http://dx.doi.org/10.4236/ojd.2014.34017
} 


\section{Keywords}

\section{Gazing, OXTR Gene, Rs53576, Social Inclusion, Observational Study}

\section{Introduction}

Social relationships are essential in human development. Having close social bonds is associated with several positive outcomes, whereas social exclusion is related to decreases in wellbeing and psychological health (Leary, 1990; Masten et al., 2009). The model of belonging regulation, which is based on the need to belong hypothesis (Baumeister \& Leary, 1995; Pickett, Gardner, \& Knowles, 2004) states that people have an evolutionary-based strong need to form close attachments with others. The model implies that a minimum of social relationships is needed to feel socially included. When the level of relationships drops below a satisfactory minimum, people can experience feelings of loneliness. To prevent this, several regulatory processes come into play when relationships satisfaction decreases. First, the processing of social cues from the environment will be enhanced in order to restore feelings of belongingness. Second, these cues will be used to display adequate social behavior in order to enhance inclusion. An essential feature for this is to attend to or to gaze at relevant social information in the environment. This cognitive-behavioral model (Gardner, Pickett, Jefferis, \& Knowles, 2005) is based on some empirical research (Baumeister, Brewer, Tice, \& Twenge, 2007; Blackhart, Baumeister, \& Twenge, 2006; Cacioppo, Norris, Decety, Monteleone, \& Nusbaum, 2009; Gere \& MacDonald, 2010; Hawkley et al., 2007), however, up till now there has been a lack of research examining associated biological markers that could explain inter-individual differences with regard to these processes. Therefore, the aim of this study is to examine whether a plausible candidate gene (the oxytocin receptor gene, OXTR) is associated with gazing behavior. The OXTR gene is an interesting candidate gene as it encodes oxytocin receptors localized in several brain structures (e.g., the amygdala, nucleus accumbens and ventral tegmental area) (Meyer-Lindenberg, 2008; Meyer-Lindenberg, Domes, Kirsch, \& Heinrichs, 2011) that are involved in social processes aimed at social bonding.

Within the belongingness literature, it is suggested that attention to meaningful social cues is a prerequisite to be able to restore a lack of inclusion (Gardner et al., 2005). As said, gazing behavior is considered to be an important mechanism to enhance the processing of social cues from the environment and to increase social bonds. Tuning to facial expressions is essential to interpret the mental state of the other. This enables humans to infer their chances on rejection or inclusion from social-emotional signs. Shortly stated, gazing or looking at facial cues rich in emotional information is important to guide effective social interactions. It has been suggested that from all facial cues the eye-region conveys the most salient information (Itier \& Batty, 2009). A prosocial neuropeptide that is highly involved in the processing of those emotion-rich cues that are needed for belonging regulation purposes is oxytocin.

Oxytocin (OT) plays a role in various social and emotional behaviors related to social inclusion (Meyer-Lindenberg, 2008). Peripheral OT levels have been related to approach behaviors aimed at social bonding (Insel, 1997; Insel \& Young, 2001) and clinical studies showed lower OT levels in psychiatric disorders characterized by social deficiencies, such as autism, anxiety and depression (Cyranowski et al., 2008; Green et al., 2001; Scantamburlo et al., 2007). Furthermore, it has been shown that intranasal OT administration has effects on various socio-emotional measures that could enhance social inclusion. Studies have shown effects on social information processing, social cognition, rewards derived from social interactions (for reviews see (Insel, 2010; Ishak, Kahloon, \& Fakhry, 2011; K. Macdonald \& T. M. Macdonald, 2010)), the desire for future social inclusion (Alvares, Hickie, \& Guastella, 2010), improved emotion identification and empathy (Bartz et al., 2010; Domes, Heinrichs, Michel, Berger, \& Herpertz, 2007; Gamer, Zurowski, \& Buchel, 2010; Hurlemann et al., 2010) and, most importantly, the amount of eye gazing (Andari et al., 2010; Guastella, Mitchell, \& Dadds, 2008). An animal study specifically showed more gazing at the eye region after OT administration compared to the non-OT condition (Dal Monte, Noble, Costa, \& Averbeck, 2014). These findings clearly show the involvement of OT in various (micro) social behaviors that could contribute to sensing social belongingness.

The OT effects in the brain come to expression as they bind to postsynaptic oxytocin brain receptors. These receptors are encoded by the OXTR gene (Gimpl \& Fahrenholz, 2001). The OXTR rs53576 single nucleotide polymorphism (SNP) is the most frequently studied variant within this gene. This SNP comprises two allelic va- 
riants, the A and G allele. The minor allele (A) has a population frequency of approximately 33\% in Caucasians. OXTR SNPs have been examined in relation to several psychiatric disorders characterized by social impairments (i.e., autism, (Jacob et al., 2007; Wermter et al., 2010; Wu et al., 2005) and social phenotypes such as loneliness (Lucht et al., 2009; van Roekel, Verhagen, Engels, Goossens, \& Scholte, 2013; van Roekel, Verhagen, Scholte, et al., 2013), sociality (Kogan et al., 2011; Tost et al., 2010), and empathy (Rodrigues, Saslow, Garcia, John, \& Keltner, 2009). This shows that genetic variation within the OXTR gene could lead to disturbances in a variety of (pro) social behaviors that interfere with belonging regulation processes. Of particular interest here is a study using video clips of romantic partners having a conversation in which observers were asked to rate the prosocial tendencies of the genotyped targets in the videos. This study revealed that individuals with the OXTR GG genotype displayed more nonverbal affiliative behaviors such as gazing at the other than A-carriers (Kogan et al., 2011).

Up till now, most OXTR gene studies have shown disadvantageous effects of the A-allele, however, there are also findings suggesting beneficial effects of this particular allele. An example is a study showing that female adolescents with the A-variant decreased in loneliness over time, whereas girls homozygous for the G-allele had higher loneliness over time (van Roekel, Verhagen, Engels, et al., 2013) and a clinical study showed that A-carriers were less likely to develop depression (Costa et al., 2009). Further, the A-allele was associated with better social capacities in children with ADHD (Park et al., 2010). Given the associations with those constructs, we will control for the effects of loneliness, depression, social anxiety, neuroticism, extraversion and talking measures.

Our aim was to study the role of the OXTR rs53576 genetic variant in processes related to belonging regulation in young adults, more specifically in gazing behaviors during two separate social interactions. Based on previous studies (in particular (Kogan et al., 2011)), we hypothesized that the OXTR G-allele would be associated with longer gazing times. Furthermore, it was hypothesized that the OXTR effect would be more pronounced in the first part of the interaction. This was based on the idea that starting an interaction with an unknown other, pursues a greater demand on social information processes as one cannot build on previous social encounters with this same person. We consider gazing behavior to be an endophenotype as this measure is more proximal to genetic functioning than the more distal and heterogeneous measures of social-behavioral traits (Bakermans-Kranenburg \& van Ijzendoorn, 2014; Gottesman \& Gould, 2003). Further, as gazing deficiencies may underlie several psychosocial traits and disorders (e.g., loneliness and social anxiety) and as gazing is being modulated by brain processes such as attention and information processing (Georgescu et al., 2013; Haxby, Hoffman, \& Gobbini, 2000), we argue that gazing behavior is a strong endophenotype.

\section{Methods}

\subsection{Procedure}

Participants were female undergraduate students recruited from the Radboud University Nijmegen, enrolled via an online computer system. Subjects entered their preferred time to join the experiment and were by this means coupled to an unfamiliar participant. A cover story was used in order to make sure that participants were unaware of the research goal. They were invited to an observation lab in which the experimenter explained the procedure. Next, the participants provided active informed consent and filled in a short questionnaire about their hobby's and favorite television programs.

Subsequently, participants were assigned to a seating arrangement consisting of two opposing seats, with a six feet distance between them. In the lamps behind each seat, two peephole cameras were hidden. Each camera recorded the face of the opposite person from a higher perspective than the eyes of the perceiver, herewith providing a clear image of gazing directions. The setting of the experiment has been successfully used before in a study measuring social interaction behavior and gazing in opposite sex-dyads (Van Straaten, Holland, Finkenauer, Hollenstein, \& Engels, 2010). When seated, the participants were given a short instruction to talk about nightlife in the city for five minutes (Task 1). After this conversation, the experimenter returned to the observation lab and participants were provided with a distraction task; they were asked to read some "quotes" that were written on paper cards and talk about them. In this task, participants focused on the written quotes instead of their interaction partner. To be able to examine the robustness of possible findings, an additional interaction task was included in the research procedure. Participants were asked to have another short conversation of 5 minutes (Task 2), talking about their favorite movies. After these conversations, the participants were led to separate 
rooms to fill out a questionnaire and to provide DNA samples by means of saliva. All participants gave their consent for genotyping. The participants received course credits and were thanked for their participation. The experiment lasted approximately 45 minutes and was approved by the ethical committee of the Radboud University Nijmegen, The Netherlands.

\subsection{Participants}

The sample in the present study consisted of 120 female undergraduate students recruited from the Radboud University Nijmegen, all of Dutch descent. Two participants were excluded from the statistical analyses due to genotyping failures. Because of the dyadic connected data, the interaction partners of these two participants were also excluded. A sample size of $\mathrm{N}=116$ (i.e., 58 dyads) with ages ranging between 17.0 and 27.0 years (mean age 19.34, SD 2.10) remained.

\subsection{Measures}

Gazing measures: Gazing and talking behaviors were coded using Noldus Observer XT software. Three coders were extensively trained to watch and code each video. They were unaware of the hypotheses of the current study and the OXTR genotype of the participants (see also (Kogan et al., 2011)). The coders were trained to document both gazing and talking behaviors. Talking behaviors were coded since talking and gazing during social interactions are related. People tend to gaze less when talking and gaze more when listening. The individual recordings were time-coded as either gaze or non-gaze (looking outside the facial region) and in talk and nontalk. $16 \%$ of the data was used for interrater reliability measures. This yielded a satisfactory reliability (kappa = 0.77 , range $=0.68$ to 0.85 ). For each participant, total gaze duration and mean gaze duration per event were calculated. Total gaze duration is the total time in ms a participant looked at the face of the interaction partner during the 5-minute task. Mean gaze duration is the average gaze duration per gaze event in ms.

OXTR genotype: DNA was isolated from saliva samples which were collected using the Oragene system (DNA Genotek Inc., Kanata, Ontario, Canada). The OXTR polymorphism (rs53576) was genotyped using Taqman analysis (Taqman Allelic Discrimination assay ID: C 3290335 10, reporter 1: VIC-A-allele, forward assay; Applied Biosystems, Nieuwerkerk a/d Ijssel, The Netherlands). Genotyping was carried out in a volume of $5 \mu \mathrm{l}$ containing $10 \mathrm{ng}$ of genomic DNA, $2.5 \mu \mathrm{l}$ of Taqman Mastermix (2×; Applied Biosytems) and $0.0625 \mu \mathrm{l}$ of the Taqman assay (40×) and $1.4375 \mu \mathrm{l}$ of Milli-Q. Each amplification was performed by an initial denaturation at $95^{\circ} \mathrm{C}$ for 12 min, followed by 40 cycles of denaturation at $92^{\circ} \mathrm{C}$ for 15 seconds and annealing/extension at $60^{\circ} \mathrm{C}$ for 1 minute, this was carried out on a 7500 Fast Real-Time PCR System. Genotypes were scored using the algorithm and software supplied by the manufacturer (Applied Biosystems). Genotyping was performed in a CCKL-accredited laboratory at the Department of Human Genetics of the Radboud University Nijmegen Medical Centre in Nijmegen. Generally, 5\% blanks as well as duplicates between plates were taken along as quality controls during genotyping. No deviations from Hardy-Weinberg equilibrium (HWE) were detected ( $p=73$ ). Due to the limited number of participants with the AA genotype, we dummy-coded the OXTR genotype into 1 (A-carrier) and 2 (GG homozygous) to maximize the power of the analyses.

Loneliness: Loneliness was measured with the Revised UCLA Loneliness Scale (R-UCLA) (Russell, Peplau, \& Cutrona, 1980). This scale consists of 20 items, measured on a 4-point scale ( $1=$ never; $4=$ often). A sample item is "I feel isolated from others" and "I lack companionship". The higher the score, the higher the level of loneliness. The scale has a high reliability ( $\alpha=0.89)$.

Depressive symptoms: Depressive symptoms were measured with a 21-item questionnaire, the Beck Depression Inventory-second edition (BDI-II; (Beck, Steer, \& Brown, 1996)), translated into Dutch (Does van der, 2002; Roelofs et al., 2013). Participants were asked about the presence of depressive symptoms during the last week. An example item is 1) "I do not feel sad”, 2) "I feel sad much of the time”, 3) "I am sad all the time”, and 4) "I am so sad or unhappy that I can't stand it”. Participants indicated on this 4-point scale which statement best fitted their feelings. The higher the score, the more depressive symptoms were present during the last week. Cronbach's alpha was 0.84 .

Social anxiety: Social anxiety symptoms were assessed with an 18-item version of the Social Phobia and Anxiety Inventory (SPAI; (de Vente, Majdandzic, Voncken, Beidel, \& Bogels, 2014)). An example item is "I feel tension when I am in the center of attention" and "I avoid social situations with strangers". The answer categories range from 1 (never) to 7 (always). The higher the score, the more socially anxious. Cronbach's alpha was 0.94. 
Personality: Neuroticism and extraversion were measured with the Dutch version of the Quick Big Five questionnaire (Goldberg, 1992; Vermulst, 2005). Each dimension was measured with 6 items on a 7-point Likert scale ranging from 1 (completely untrue) to 7 (completely true). Neuroticism was assessed with items as "worried" and extraversion with items as "talkative". Higher scores indicate higher levels of neuroticism and extraversion. Cronbach's alpha was 0.82 for neuroticism and 0.90 for extraversion.

\subsection{Statistical Analyses}

Based on the fact that the dyads provided clustered data that are not independent (Kuntsche \& Jordan, 2006), Mplus was used (Muthén \& Muthén, 1998-2007). Regression analyses were conducted with the OXTR gene as independent variable and total gaze duration and mean gaze duration per event as dependent variables.

Two models were tested for Task 1 and Task 2 separately. In the first step, the simple model without covariates was tested to estimate the main effect of the OXTR gene on gazing behaviors in Task 1, both on total gaze duration and mean gaze duration per event. Second, the covariates loneliness, depressive symptoms, social anxiety, neuroticism, extraversion and talking duration of the other and self were entered in the model as covariates. Additional analyses were performed to test whether OXTR gene effects were differently associated with the first and second halves of the 5-minute interaction Task 1 . Therefore, the interaction time was split into two halves (first half: 0 to150 seconds, second half: 151 to 301 seconds). The same models with the same covariates were tested for the separate halves.

To examine the robustness of findings of Task 1, the same models were tested for interaction Task 2 and the separate halves of this task, again for total gaze duration and mean gaze duration.

\section{Results}

\subsection{Descriptive Statistics}

Means and standard deviations for the gazing measures are presented in Table 1. Paired T-tests showed that total gaze duration differed significantly between Tasks 1 and 2 in that gazing times were longer in the first interaction task $(\mathrm{t}(114)=4.92, p<0.001)$. More specifically, gazing times differed only significantly for the first halves of both interaction tasks ( $\mathrm{t}(114)=5.78, p<0.001)$ and not for the second halves $(\mathrm{t}(114)=1.94, p>$ 0.05). Mean gaze duration per event was similar in both interaction tasks.

The genotype frequencies for the OXTR genotype were as follows: 69 participants (59.5\%) were A-carrier and 47 participants (40.5\%) were homozygous for the G-allele. Independent T-tests showed that A-carriers did not differ from GG-carriers in the gazing or talking measures, except for the mean gaze duration per event for the first half of task $1(\mathrm{t}(113)=2.88, p<0.01)$, with A-carriers displaying longer mean gazing times (i.e., mean duration per event was $1.71(\mathrm{SD}=0.31)$ seconds in A-carriers versus a mean duration of $1.55(\mathrm{SD}=0.28)$ seconds in GG homozygous individuals).

The gazing and talking behaviors were all significantly positively correlated (r's ranging between 0.19 and 0.95), except for gaze duration (first half of Task 2) and talking behavior of the other (Task 1) and vice versa (gaze duration in the first half of Task 1 was unrelated to the other's talking behavior during Task 2). Further, it was consistently found that gazing behavior was negatively correlated with own talking behavior (r's ranging between -0.22 and -0.52 , all $p<0.05$ ), whereas it was positively correlated with talking behavior of the partner ( $\mathrm{r}$ 's ranging between 0.20 and 0.52, all $p<0.05$ ). In Table 2, descriptives and correlations between control variables are presented. All control variables were significantly correlated, with just one exception; depression and extraversion were not significantly correlated. All others were in the expected directions.

\subsection{Model Findings for Total Gaze Duration and Gaze Duration per Event in Interaction Task 1}

First, main OXTR gene effects on total gazing time during the first interaction task were tested, without and with covariates. No significant main OXTR gene effects were present (results not shown). Second, the influence of the OXTR gene on mean gaze duration per event was examined. In the simple model, a significant main effect of the OXTR gene was found indicating that A-carriers displayed longer mean gaze duration per event compared to GG-carriers (Table 3, Model 1). Additional analyses for the first and second halves of interaction Task 1 separately, yielded that the gene effects were only present in the first half of the interaction and not in the second 
Table 1. Means (standard deviations) and paired t-tests for total gaze duration and gaze duration per event $(\mathrm{N}=114)$.

\begin{tabular}{cccc}
\hline & Means (SD) & Means (SD) & Paired T-test \\
\cline { 2 - 4 } & Interaction Task 1 & Interaction Task 2 & \\
\hline Total Duration Gazing & $199.50(48.58)$ & $184.07(51.58)$ & $\mathrm{T}(114)=4.92 * * *$ \\
Total Duration Gazing, First Half & $103.99(23.96)$ & $92.82(25.77)$ & $\mathrm{T}(114)=5.78^{* * *}$ \\
Total Duration Gazing, Second Half & $94.87(26.92)$ & $90.61(29.01)$ & $\mathrm{T}(114)=1.94$ \\
Mean Gazing Duration per Event & $1.64(0.30)$ & $1.67(0.32)$ & $\mathrm{T}(114)=-0.84$ \\
Mean Gazing Duration per Event, First Half & $1.64(0.30)$ & $1.64(0.36)$ & $\mathrm{T}(114)=0.36$ \\
Mean Gazing Duration per Event, Second Half & $1.65(0.35)$ & $1.70(0.34)$ & $\mathrm{T}(114)=-1.57$ \\
\hline
\end{tabular}

${ }^{*} p<0.05 .{ }^{*} p<0.01 . * * * p<0.001$.

Table 2. Means (standard deviations), ranges and correlations among control variables $(\mathrm{N}=116)$.

\begin{tabular}{|c|c|c|c|c|c|c|}
\hline & Mean (SD) & Min-Max & 1. Neuroticism & 2. Extraversion & 3. Social Anxiety & 4. Loneliness \\
\hline 1. Neuroticism & $3.77(1.02)$ & $1.50-6.83$ & - & & & \\
\hline 2. Extraversion & $4.97(1.07)$ & $2.17-7.00$ & $-0.36^{* * *}$ & - & & \\
\hline 3. Social Anxiety & $2.84(0.79)$ & $1.31-5.59$ & $0.36^{* * *}$ & $-0.52 * * *$ & - & \\
\hline 4. Loneliness & $1.65(0.36)$ & $1.20-3.45$ & $0.31^{* *}$ & $-0.44^{* * *}$ & $0.41 * * *$ & - \\
\hline 5. Depression & $0.25(0.25)$ & $0.00-1.67$ & $0.47^{* * *}$ & -0.09 & $0.22 *$ & $0.48^{* * *}$ \\
\hline
\end{tabular}

${ }^{*} p<0.05 .{ }^{* *} p<0.01 .{ }^{* * *} p<0.001$.

Table 3. Regression effects of the OXTR gene on mean gazing duration per event (beta's, sd's, r2) for interaction Task 1 (total), and for the first and second halves of interaction Task 1.

\begin{tabular}{ccccccccccc}
\hline & \multicolumn{3}{c}{ Interaction Task 1 } & \multicolumn{3}{c}{ Task 1: First half interaction } & \multicolumn{3}{c}{ Task 1: Second half interaction } \\
\hline & $\mathrm{N}$ & $\beta(\mathrm{SE})$ & $\mathrm{R} 2$ & $\mathrm{~N}$ & $\beta(\mathrm{SE})$ & $\mathrm{R} 2$ & $\mathrm{~N}$ & $\beta(\mathrm{SE})$ \\
\hline Model 1 & 116 & $-0.17(0.08)^{*}$ & 0.03 & 116 & $-0.27(0.09)^{* *}$ & 0.07 & 116 & $-0.11(0.08)$ & 0.01 \\
Model 2 & 116 & $-0.18(0.08)^{*}$ & $0.22^{* *}$ & 116 & $-0.29(0.08)^{* * *}$ & $0.23^{* * *}$ & 116 & $-0.11(0.08)$ & $0.18^{* *}$ \\
\hline
\end{tabular}

Note. Model 1 is the simple model without covariates. In Model 2, analyses were controlled for neuroticism, extraversion, social anxiety, loneliness, depressive symptoms, and talking behaviors during the interaction. OXTR; $1=\mathrm{AA} / \mathrm{AG}, 2=\mathrm{GG} .{ }^{*} p<0.05 .{ }^{* *} p<0.01 .{ }^{* * *} p<0.001$.

half. After controlling for the covariates (Table 3, Model 2), the OXTR gene effect remained significant for mean gazing duration per event for the total interaction and for the first half of the interaction. Again, no OXTR effects were found for the second half of the interaction.

\subsection{Model Findings for Total Gaze Duration and Gaze Duration per Event in the Second Interaction Task}

To assess the consistency of the findings of Task 1, we conducted similar analyses in the second interaction task. We found predominantly similar findings for both tasks. Again, no gene effects were found for total gaze duration (results not shown).

In contrast to Task 1, no OXTR genotype effects were found for mean gaze duration per event in the simple models (Table 4, model 1). After controlling for several covariates (Table 4, Model 2), significant gene effects were present for the total interaction and the first half of this interaction, showing longer mean gazing times per event in A-carriers than in GG-carriers. For the second half of this task, again no main gene effects were observed in relation to mean gaze duration.

\section{Discussion}

This observational study aimed at examining OXTR gene effects on gazing behaviors during social interactions between female young adults who were not acquainted. Our findings are the first to show an effect of the OXTR 
Table 4. Regression effects of the OXTR gene on mean gazing duration per event (beta's, sd's, r2) for interaction Task 2 (total), and for the first and second halves of interaction Task 2.

\begin{tabular}{ccccccccccc}
\hline & \multicolumn{3}{c}{ Interaction Task 2 } & & \multicolumn{3}{c}{ Task 2: First half interaction } & \multicolumn{2}{c}{ Task 2: Second half interaction } \\
\hline & $\mathrm{N}$ & $\beta(\mathrm{SE})$ & $\mathrm{R} 2$ & $\mathrm{~N}$ & $\beta(\mathrm{SE})$ & $\mathrm{R} 2$ & $\mathrm{~N}$ & $\beta(\mathrm{SE})$ & $\mathrm{R} 2$ \\
Model 1 & 116 & $-0.10(0.09)$ & 0.01 & 116 & $-0.12(0.09)$ & 0.01 & 116 & $-0.10(0.10)$ & 0.01 \\
Model 2 & 116 & $-0.17(0.08)^{*}$ & $0.32^{* * *}$ & 112 & $-0.19(0.07)^{*}$ & $0.28 * * *$ & 112 & $-0.15(0.08)$ & $0.32 * * *$ \\
\hline
\end{tabular}

Note. Model 1 is the simple model without covariates. In Model 2, analyses were controlled for neuroticism, extraversion, social anxiety, loneliness, depressive symptoms, and talking behaviors during the interaction. OXTR; $1=\mathrm{AA} / \mathrm{AG}, 2=\mathrm{GG} .{ }^{*} p<0.05 .{ }^{* *} p<0.01 .{ }^{* * *} p<0.001$.

rs53576 variant on the duration of gazing behaviors in a real-time interaction design. We did find an OXTR main effect for mean gaze duration per event, but not for the total duration of gazing. This effect was especially present in the beginning of the conversation and not in the second half of the interaction task. In the second interaction task we could confirm these findings, in that the OXTR gene was associated with gaze duration per event in the first half of the interaction task, but only when the covariates were included in the model.

In contrast to our hypothesis, this study showed that the A-allele of the rs53576 SNP was associated with longer mean gazing times, and not the GG genotype. Previous studies have mostly described the A-allele to be the risk allele for several characteristics related to social functioning; therefore we expected shorter gazing times. As it has been suggested that the OXTR gene modulates social behavior that is under control of brain OT (Bakermans-Kranenburg \& van Ijzendoorn, 2014), we reason that it could well be that a compensatory mechanism comes into play: A-allele carriers may have less proficient OT signaling in the brain and therefore need longer gazing times at the face of the interaction partner to be able to pick up social cues that are needed for efficient social interaction. Although the exact underlying molecular mechanisms are not yet understood, we argue that, based on the idea that the A-allele is affecting the OT receptor in such a way that the receptors are less efficient in transporting oxytocin into the brain, longer gazing times are needed to obtain the same net levels of brain oxytocin. Further along this line, higher levels of brain oxytocin might be needed to be able to adequately read or interpret social facial cues. This is illustrated by a study showing that exogenous OT facilitates social information processing (Hollander et al., 2007) and gazing (Andari et al., 2010; Guastella et al., 2008), abilities that are needed to process information from eye contact. Moreover, research on autism, a disorder that is characterized by difficulties in social interactions, has suggested that reduced OT function might be related to the social deficits observed in autism (Tansey et al., 2010). It could be reasonably argued that longer gazing leads to an up regulation of brain oxytocin which in turn is important in interpreting social cues.

An interesting finding is that the OXTR variant was only associated with mean gaze duration per event and not with individual's total gaze duration. This indicates that during the 5-minute conversation, the individuals do not differ in the total amount of time that they are looking at their interaction partner, however, it indicates that the actual time per event that they look at the other differs significantly between genotypes. This is a puzzling result and could not be explained by previous studies. It may suggest that the shorter gaze duration per event in GG homozygote's is sufficient for them to extract the necessary social information from their partner's face for successful social interaction. This may again be indicative for better OT efficiency in the brain. Another notable finding is that the genetic associations were particularly present during the first halves of the conversations. As gazing literature on this topic is limited, we speculate that this mainly represents an OXTR effect of tuning to the partner and topic. These findings suggest that especially during the first few minutes, A-carriers need more time for social reconciliation processes.

An interesting question then is how our findings relate to Kogans work in which also an association was observed for this particular SNP and gazing behavior. Kogan and colleagues (2011) showed that individuals with the GG genotype were rated as more prosocial by others and displayed more nonverbal cues, with one of the components being gaze behavior. Gaze behavior was defined as the amount of eye contact (rated on a 5-point scale: $0=$ no eye contact, 5 = eye contact during whole video fragment). We cannot directly compare their findings with ours, as their analyses were not conducted on a single direct gaze measure as outcome variable. In addition, we microcoded the behaviors of interest (in ms per gazing event), whereas Kogan et al. (2011) used macro coding for gazing. Next to this, their methodology differed substantially from ours, in that observers were asked to rate the behavior of the genotyped participants within the videos whereas we conducted analyses on the behavior of 
the genotyped subjects themselves. Taken together, the seemingly opposite findings in both studies could be easily attributed to these differences. Though, replication of these studies is highly warranted, especially to gain insight in the functional relevance of the OXTR alleles.

A strength of the present study is the use of an observational design in which our outcome measure of gazing behavior was assessed multiple times. In addition to this, the interrater reliability between the coders of all video-fragments was satisfactory. Next to this, this is the first study examining the rs53576 genetic variant in relation to a real-time interaction design. However, one should keep in mind a few limitations. The first is the use of a single-SNP paradigm. Despite several studies having shown significant effects for rs53576 in relation to various social emotional measures, the explained variance of a trait by a single SNP is limited. Testing multiple genetic variants and haplotypes within the OXTR gene or genes in biologically related systems (e.g., arginine vasopressin) could lead to a more thorough understanding of genetic effects on gazing behaviors. A second limitation is the selected sample, consisting of highly educated females. Third, our sample size was relatively small. However, the gazing events were assessed multiple times within the 5-minute frame which increases the reliability of the outcome to a great extent. The use of two separate interactions and the narrow-defined description of our gazing (endo) phenotype gives little space for measurement noise; therefore we are confident about the involvement of the OXTR SNP in gazing behavior, despite the effect size being small.

\section{Conclusion}

Eye-gazing during social interactions is partly influenced by the A118G variant of the OXTR gene. More specifically, the A-allele was responsible for longer mean gazing times in the female participants, especially during the first parts of the conversations. This was found in two separate real-life interaction tasks. Although we should interpret these findings with caution, we speculate that the association of the A-allele being associated with longer mean gaze duration could indicate that these individuals need longer gazing times to be able to tune in the conversation and into the partner and need more time to make inferences of facial cues. When experiencing an increased need to belong, the capacity of adequately reading the others' face is, amongst others, essential to establish social inclusion and to avoid loneliness. The exact underlying mechanism, the functional relevance of the gene and the relation with OT levels in the brain, need to be further explored.

\section{Acknowledgements}

We specially thank Marlies Naber and Angelien Heister for setting up and performing genotyping and the research group of Multifactorial Diseases, Department of Human Genetics, Radboud University Nijmegen Medical Centre, The Netherlands.

\section{References}

Alvares, G. A., Hickie, I. B., \& Guastella, A. J. (2010). Acute Effects of Intranasal Oxytocin on Subjective and Behavioral Responses to Social Rejection. Experimental and Clinical Psychopharmacology, 18, 316-321. http://dx.doi.org/10.1037/a0019719

Andari, E., Duhamel, J. R., Zalla, T., Herbrecht, E., Leboyer, M., \& Sirigu, A. (2010). Promoting Social Behavior with Oxytocin in High-Functioning Autism Spectrum Disorders. Proceedings of the National Academy of Sciences of the United States of America, 107, 4389-4394. http://dx.doi.org/10.1073/pnas.0910249107

Bakermans-Kranenburg, M. J., \& van Ijzendoorn, M. H. (2014). A Sociability Gene? Meta-Analysis of Oxytocin Receptor Genotype Effects in Humans. Psychiatric Genetics, 24, 45-51. http://dx.doi.org/10.1097/YPG.0b013e3283643684

Bartz, J. A., Zaki, J., Bolger, N., Hollander, E., Ludwig, N. N., Kolevzon, A., \& Ochsner, K. N. (2010). Oxytocin Selectively Improves Empathic Accuracy. Psychological Science, 21, 1426-1428. http://dx.doi.org/10.1177/0956797610383439

Baumeister, R. F., \& Leary, M. R. (1995). The Need to Belong: Desire for Interpersonal Attachments as a Fundamental Human Motivation. Psychological Bulletin, 117, 497-529. http://dx.doi.org/10.1037/0033-2909.117.3.497

Baumeister, R. F., Brewer, L. E., Tice, D. M., \& Twenge, J. M. (2007). Thwarting the Need to Belong: Understanding the Interpersonal and Inner Effects of Social Exclusion. Social and Personality Psychology Compass, 1, 506-520. http://dx.doi.org/10.1111/j.1751-9004.2007.00020.x

Beck, A. T., Steer, R. A., \& Brown, G. K. (1996). Beck Depression Inventory (2nd ed.). San Antonio, TX: The Psychological Corporation.

Blackhart, G. C., Baumeister, R. F., \& Twenge, J. M. (2006). Rejection’s Impact on Self-Defeating, Prosocial, Antisocial, 
and Self-Regulatory Behaviors. In K. D. Vohs \& E. J. Finkel, (Eds.), Self and Relationships: Connecting Intrapersonal and Interpersonal Processes (pp. 237-253). New York: Guilford Press.

Cacioppo, J. T., Norris, C. J., Decety, J., Monteleone, G., \& Nusbaum, H. (2009). In the Eye of the Beholder: Individual Differences in Perceived Social Isolation Predict Regional Brain Activation to Social Stimuli. Journal of Cognitive Neuroscience, 21, 83-92. http://dx.doi.org/10.1162/jocn.2009.21007

Costa, B., Pini, S., Gabelloni, P., Abelli, M., Lari, L., Cardini, A. et al. (2009). Oxytocin Receptor Polymorphisms and Adult Attachment Style in Patients with Depression. Psychoneuroendocrinology, 34, 1506-1514. http://dx.doi.org/10.1016/j.psyneuen.2009.05.006

Cyranowski, J. M., Hofkens, T. L., Frank, E., Seltman, H., Cai, H. M., \& Amico, J. A. (2008). Evidence of Dysregulated Peripheral Oxytocin Release among Depressed Women. Psychosomatic Medicine, 70, 967-975. http://dx.doi.org/10.1097/PSY.0b013e318188ade4

Dal Monte, O., Noble, P. L., Costa, V. D., \& Averbeck, B. B. (2014). Oxytocin Enhances Attention to the Eye Region in Rhesus Monkeys. Frontiers in Neuroscience, 8, 41. http://dx.doi.org/10.3389/fnins.2014.00041

De Vente, W., Majdandzic, M., Voncken, M. J., Beidel, D. C., \& Bogels, S. M. (2014). The Spai-18, a Brief Version of the Social Phobia and Anxiety Inventory: Reliability and Validity in Clinically Referred and Non-Referred Samples. Journal of Anxiety Disorders, 28, 140-147. http://dx.doi.org/10.1016/j.janxdis.2013.05.003

Does van der, A. J. W. (2002). BDI-II-NL Handleiding: De Nederlandse Versie Van de Beck Depression Inventory. (2nd ed.). Lisse: Harcourt Test Publishers.

Domes, G., Heinrichs, M., Michel, A., Berger, C., \& Herpertz, S. C. (2007). Oxytocin Improves “Mind-Reading” in Humans. Biological Psychiatry, 61, 731-733. http://dx.doi.org/10.1016/j.biopsych.2006.07.015

Gamer, M., Zurowski, B., \& Büchel, C. (2010). Different Amygdala Subregions Mediate Valence-Related and Attentional Effects of Oxytocin in Humans. Proceedings of the National Academy of Sciences of the United States of America, 107, 9400-9405. http://dx.doi.org/10.1073/pnas.1000985107

Gardner, W. L., Pickett, C. L., Jefferis, V., \& Knowles, M. (2005). On the Outside Looking In: Loneliness and Social Monitoring. Personality and Social Psychology Bulletin, 31, 1549-1560. http://dx.doi.org/10.1177/0146167205277208

Georgescu, A. L., Kuzmanovic, B., Schilbach, L., Tepest, R., Kulbida, R., Bente, G., \& Vogeley, K. (2013). Neural Correlates of "Social Gaze” Processing in High-Functioning Autism under Systematic Variation of Gaze Duration. Neuroimage: Clinical, 3, 340-351. http://dx.doi.org/10.1016/j.nicl.2013.08.014

Gere, J., \& MacDonald, G. (2010). An Update of the Empirical Case for the Need to Belong. The Journal of Individual Psychology, 66, 93-115.

Gimpl, G., \& Fahrenholz, F. (2001). The Oxytocin Receptor System: Structure, Function, and Regulation. Physiology Review, 81, 629-683.

Goldberg, L. R. (1992). The Development of Markers for the Big-Five Factor Structure. Psychological Assessment, 4 , $26-42$. http://dx.doi.org/10.1037/1040-3590.4.1.26

Gottesman, I., \& Gould, T. D. (2003). The Endophenotype Concept in Psychiatry: Etymology and Strategic Intentions. American Journal of Psychiatry, 160, 636-645. http://dx.doi.org/10.1176/appi.ajp.160.4.636

Green, L., Fein, D., Modahl, C., Feinstein, C., Waterhouse, L., \& Morris, M. (2001). Oxytocin and Autistic Disorder: Alterations in Peptide Forms. Biological Psychiatry, 50, 609-613. http://dx.doi.org/10.1016/S0006-3223(01)01139-8

Guastella, A. J., Mitchell, P. B., \& Dadds, M. R. (2008). Oxytocin Increases Gaze to the Eye Region of Human Faces. Biological Psychiatry, 63, 3-5. http://dx.doi.org/10.1016/j.biopsych.2007.06.026

Hawkley, L. C., Preacher, K. J., \& Cacioppo, J. T. (2007). Multilevel Modeling of Social Interactions and Mood in Lonely and Socially Connected Individuals: The Macarthur Social Neuroscience Studies. In A. D. Ong, \& Van Dulmen, M. (Eds.), Oxford Handbook of Methods in Positive Psychology (pp. 559-575). New York: Oxford University Press.

Haxby, J. V., Hoffman, E. A., \& Gobbini, M. I. (2000). The Distributed Human Neural System for Face Perception. Trends in Cognitive Sciences, 4, 223-233. http://dx.doi.org/10.1016/S1364-6613(00)01482-0

Hollander, E., Bartz, J., Chaplin, W., Phillips, A., Sumner, J., Soorya, L. et al. (2007). Oxytocin Increases Retention of Social Cognition in Autism. Biological Psychiatry, 61, 498-503. http://dx.doi.org/10.1016/j.biopsych.2006.05.030

Hurlemann, R., Patin, A., Onur, O. A., Cohen, M. X., Baumgartner, T., Metzler, S. et al. (2010). Oxytocin Enhances Amygdala-Dependent, Socially Reinforced Learning and Emotional Empathy in Humans. Journal of Neuroscience, 30, 49995007. http://dx.doi.org/10.1523/JNEUROSCI.5538-09.2010

Insel, T. R. (1997). A Neurobiological Basis of Social Attachment. American Journal of Psychiatry, 154, 726-735.

Insel, T. R. (2010). The Challenge of Translation in Social Neuroscience: A Review of Oxytocin, Vasopressin, and Affiliative Behavior. Neuron, 65, 768-779. http://dx.doi.org/10.1016/j.neuron.2010.03.005 
Insel, T. R., \& Young, L. J. (2001). The Neurobiology of Attachment. Nature Reviews Neuroscience, 2, 129-136. http://dx.doi.org/10.1038/35053579

Ishak, W. W., Kahloon, M., \& Fakhry, H. (2011). Oxytocin Role in Enhancing Well-Being: A Literature Review. Journal of Affective Disorders, 130, 1-9. http://dx.doi.org/10.1016/j.jad.2010.06.001

Itier, R. J., \& Batty, M. (2009). Neural Bases of Eye and Gaze Processing: The Core of Social Cognition. Neuroscience and Biobehavioral Reviews, 33, 843-863. http://dx.doi.org/10.1016/j.neubiorev.2009.02.004

Jacob, S., Brune, C. W., Carter, C. S., Leventhal, B. L., Lord, C., \& Cook Jr., E. H. (2007). Association of the Oxytocin Receptor Gene (OXTR) in Caucasian Children and Adolescents with Autism. Neuroscience Letters, 417, 6-9. http://dx.doi.org/10.1016/j.neulet.2007.02.001

Kogan, A., Saslow, L. R., Impett, E. A., Oveis, C., Keltner, D., \& Saturn, S. R. (2011). Thin-Slicing Study of the Oxytocin Receptor (OXTR) Gene and the Evaluation and Expression of the Prosocial Disposition. Proceedings of the National Academy of Sciences of the United States of America, 108, 19189-19192. http://dx.doi.org/10.1073/pnas.1112658108

Kuntsche, E., \& Jordan, M. D. (2006). Adolescent Alcohol and Cannabis Use in Relation to Peer and School Factors: Results of Multilevel Analyses. Drug and Alcohol Dependence, 84, 167-174. http://dx.doi.org/10.1016/j.drugalcdep.2006.01.014

Leary, M. R. (1990). Responses to Social Exclusion: Social Anxiety, Jealousy, Loneliness, Depression, and Low Self-Esteem. Journal of Social and Clinical Psychology, 9, 221-229. http://dx.doi.org/10.1521/jscp.1990.9.2.221

Lucht, M. J., Barnow, S., Sonnenfeld, C., Rosenberger, A., Grabe, H. J., Schroeder, W. et al. (2009). Associations between the Oxytocin Receptor Gene (OXTR) and Affect, Loneliness and Intelligence in Normal Subjects. Progress in Neuro-Psychopharmacology and Biological Psychiatry, 33, 860-866. http://dx.doi.org/10.1016/j.pnpbp.2009.04.004

Macdonald, K., \& Macdonald, T. M. (2010). The Peptide That Binds: A Systematic Review of Oxytocin and Its Prosocial Effects in Humans. Harvard Review of Psychiatry, 18, 1-21. http://dx.doi.org/10.3109/10673220903523615

Masten, C. L., Eisenberger, N. I., Borofsky, L. A., Pfeifer, J. H., McNealy, K., Mazziotta, J. C., \& Dapretto, M. (2009). Neural Correlates of Social Exclusion during Adolescence: Understanding the Distress of Peer Rejection. Social Cognitive and Affective Neuroscience, 4, 143-157. http://dx.doi.org/10.1093/scan/nsp007

Meyer-Lindenberg, A. (2008). Impact of Prosocial Neuropeptides on Human Brain Function. Progress in Brain Research, 170, 463-470. http://dx.doi.org/10.1016/S0079-6123(08)00436-6

Meyer-Lindenberg, A., Domes, G., Kirsch, P., \& Heinrichs, M. (2011). Oxytocin and Vasopressin in the Human Brain: Social Neuropeptides for Translational Medicine. Nature Reviews Neuroscience, 12, 524-538. http://dx.doi.org/10.1038/nrn3044

Muthén, L. K., \& Muthén, B. O. (1998-2007). Mplus User’s Guide (5th ed.). Los Angeles, CA: Muthén \& Muthén.

Park, J., Willmott, M., Vetuz, G., Toye, C., Kirley, A., Hawi, Z. et al. (2010). Evidence That Genetic Variation in the Oxytocin Receptor (OXTR) Gene Influences Social Cognition in ADHD. Progress in Neuro-Psychopharmacological and Biological Psychiatry, 34, 697-702. http://dx.doi.org/10.1016/j.pnpbp.2010.03.029

Pickett, C. L., Gardner, W. L., \& Knowles, M. (2004). Getting a Cue: The Need to Belong and Enhanced Sensitivity to Social Cues. Personality and Social Psychology Bulletin, 30, 1095-1107. http://dx.doi.org/10.1177/0146167203262085

Rodrigues, S. M., Saslow, L. R., Garcia, N., John, O. P., \& Keltner, D. (2009). Oxytocin Receptor Genetic Variation Relates to Empathy and Stress Reactivity in Humans. Proceedings of the National Academy of Sciences of the United States of America, 106, 21437-21441. http://dx.doi.org/10.1073/pnas.0909579106

Roelofs, J., van Breukelen, G., de Graaf, L. E., Beck, A. T., Arntz, A., \& Huibers, M. J. H. (2013). Norms for the Beck Depression Inventory (BDI-II) in a Large Dutch Community Sample. Journal of Psychopathology and Behavioral Assessment, 35, 93-98. http://dx.doi.org/10.1007/s10862-012-9309-2

Russell, D., Peplau, L. A., \& Cutrona, C. E. (1980). The Revised UCLA Loneliness Scale: Concurrent and Discriminant Validity Evidence. Journal of Personality and Social Psychology, 39, 472-480. http://dx.doi.org/10.1037/0022-3514.39.3.472

Scantamburlo, G., Hansenne, M., Fuchs, S., Pitchot, W., Marechal, P., Pequeux, C. et al. (2007). Plasma Oxytocin Levels and Anxiety in Patients with Major Depression. Psychoneuroendocrinology, 32, 407-410.

http://dx.doi.org/10.1016/j.psyneuen.2007.01.009

Tansey, K. E., Brookes, K. J., Hill, M. J., Cochrane, L. E., Gill, M., Skuse, D. et al. (2010). Oxytocin Receptor (OXTR) Does Not Play a Major Role in the Aetiology of Autism: Genetic and Molecular Studies. Neuroscience Letters, 474, $163-167$. http://dx.doi.org/10.1016/j.neulet.2010.03.035

Tost, H., Kolachana, B., Hakimi, S., Lemaitre, H., Verchinski, B. A., Mattay, V. S. et al. (2010). A Common Allele in the Oxytocin Receptor Gene (OXTR) Impacts Prosocial Temperament and Human Hypothalamic-Limbic Structure and Function. Proceedings of the National Academy of Sciences of the United States of America, 107, 13936-13941. http://dx.doi.org/10.1073/pnas.1003296107

van Roekel, E., Verhagen, M., Engels, R. C., Goossens, L., \& Scholte, R. H. (2013). Oxytocin Receptor Gene (OXTR) in Re- 
lation to Loneliness in Adolescence: Interactions with Sex, Parental Support, and DRD2 and 5-HTTLPR Genotypes. Psychiatric Genetics, 23, 204-213. http://dx.doi.org/10.1097/YPG.0b013e328363f631

van Roekel, E., Verhagen, M., Scholte, R. H., Kleinjan, M., Goossens, L., \& Engels, R. C. (2013). The Oxytocin Receptor Gene (OXTR) in Relation to State Levels of Loneliness in Adolescence: Evidence for Micro-Level Gene-Environment Interactions. PLoS ONE, 8, e77689. http://dx.doi.org/10.1371/journal.pone.0077689

van Straaten, I., Holland, R. W., Finkenauer, C., Hollenstein, T., \& Engels, R. C. (2010). Gazing Behavior During MixedSex Interactions: Sex and Attractiveness Effects. Archives of Sexual Behavior, 39, 1055-1062. http://dx.doi.org/10.1007/s10508-009-9482-x

Vermulst, A. A., \& Gerris, J. R. M. (2005). QBF: Quick Big Five Persoonlijkheidstest Handleiding (Quick Big Five Personality Test Manual). Leeuwarden: LDC.

Wermter, A. K., Kamp-Becker, I., Hesse, P., Schulte-Korne, G., Strauch, K., \& Remschmidt, H. (2010). Evidence for the Involvement of Genetic Variation in the Oxytocin Receptor Gene (OXTR) in the Etiology of Autistic Disorders on HighFunctioning Level. American Journal of Medical Genetics Part B: Neuropsychiatric Genetics, 153B, 629-639.

Wu, S., Jia, M., Ruan, Y., Liu, J., Guo, Y., Shuang, M. et al. (2005). Positive Association of the Oxytocin Receptor Gene (OXTR) with Autism in the Chinese Han Population. Biological Psychiatry, 58, 74-77. http://dx.doi.org/10.1016/j.biopsych.2005.03.013 
Scientific Research Publishing (SCIRP) is one of the largest Open Access journal publishers. It is currently publishing more than 200 open access, online, peer-reviewed journals covering a wide range of academic disciplines. SCIRP serves the worldwide academic communities and contributes to the progress and application of science with its publication.

Other selected journals from SCIRP are listed as below. Submit your manuscript to us via either submit@scirp.org or Online Submission Portal.
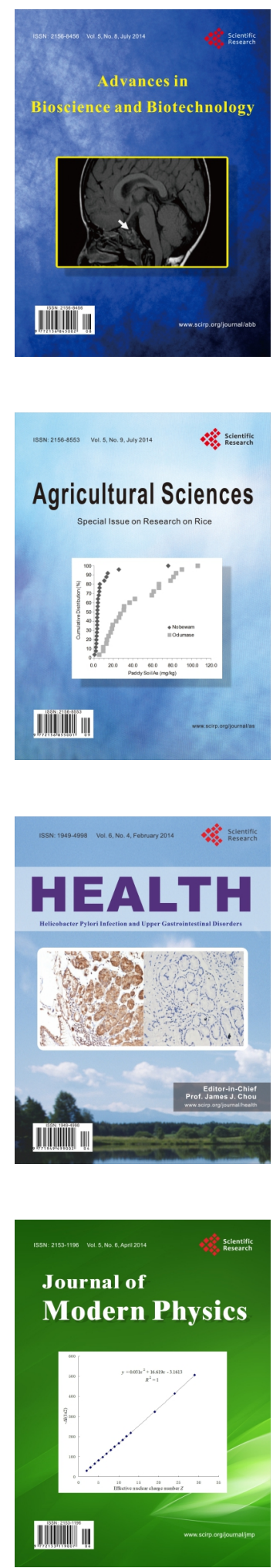
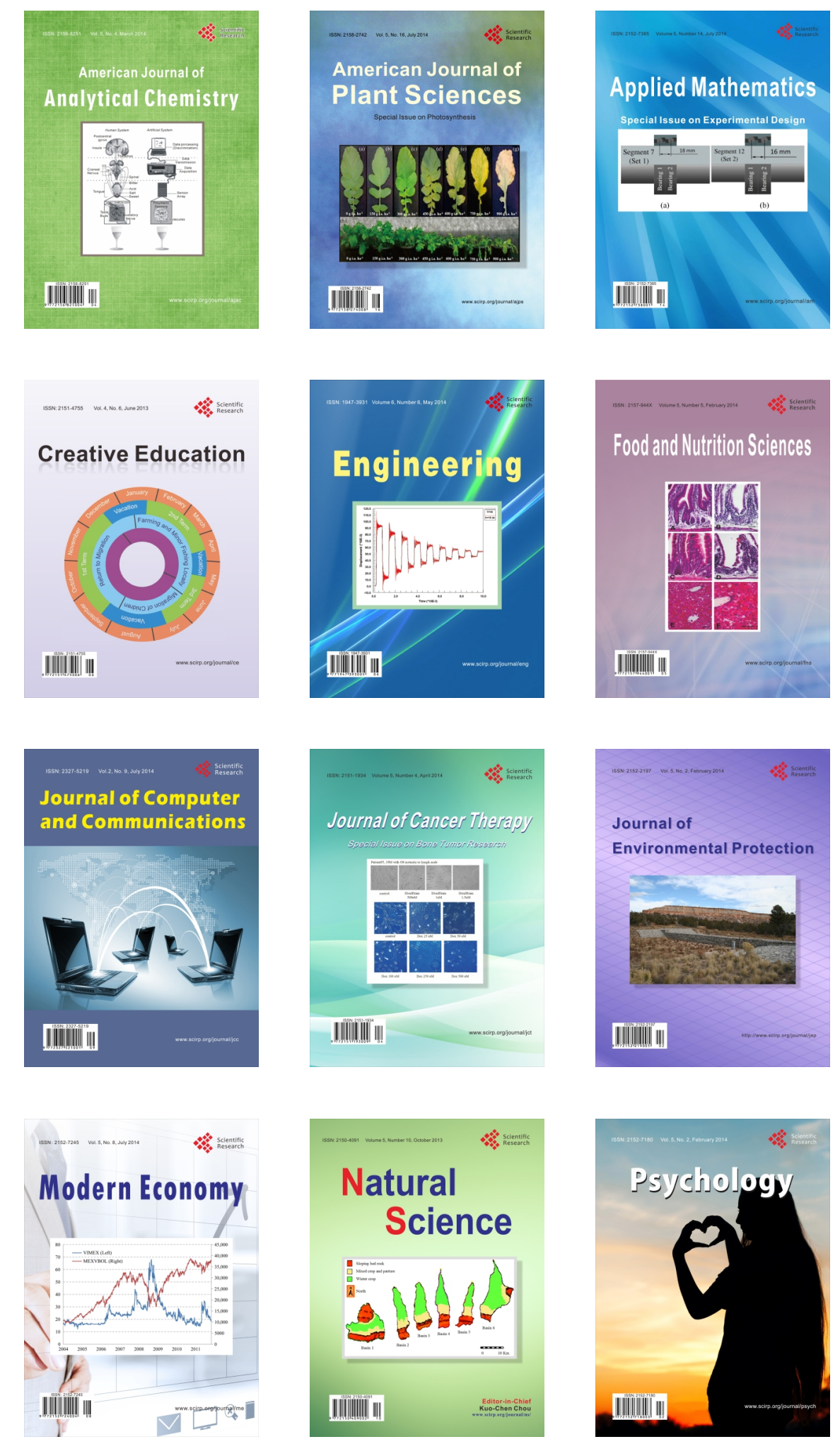